\title{
CFD Simulation of Turbulent Air Flow in Diffuser and it's Effect on Fluid Properties
}

\author{
Ali Hamzah Kadhim ALShabbani ${ }^{1}$, Kassim Kadhim Hameed Al-shemary ${ }^{2}$, Husham M.Al.Tameemi ${ }^{3}$ \\ ${ }^{1}$ Chem. Eng. Dept., College of Eng., Al-Qadisiyah University \\ ${ }^{2}$ Mech. Eng. Dept., College of Eng., Al-Qadisiyah University
}

\begin{abstract}
The work reported in this article investigates the influences of inlet boundary conditions on the fluid properties which simulated by ANSYS (APDL). An axial fixed vane swirling diffuser with 12 vanes of declining angle 6 degree is used for the primary air flow. For the swirling air flow inlet boundary condition specifications, the turbulence model used is k-omega turbulence model. The conventional method is to specify the inlet velocities based on totally constant axial and tangential momentum fluxes.
\end{abstract}

Keywords: ANSYS, air, diffuser, k-omega turbulence model, 12 vanes.

\section{Introduction}

Swirling flows are widely used in many engineering applications such as gas turbine combustion chambers and other high intensity combustors. The turbulent flow is used to improve the location of the separation point. Moreover, the laminar boundary layer can be detached easier compare with turbulent one from the diffuser surface. Many researchers studied the effect of turbulent flow on velocity and pressure distribution. Kreith and Margolis [1] first proved that the use of swirl in tube flows could augment surface heat transfer rates relative to flows without swirl. In combustion and burners, the swirling flow is used extensively for flame stabilization due to the enhanced mixing processes between the supplied air and the recirculated high temperature gas [2,3]. One common method of generating a swirling jet is by employing a swirling inlet diffuser. Visser and Plessis [4] investigated flow patterns influenced by different diffuser angles and swirl numbers. The swirling flow can also be influenced by the air inlet geometry[5]. Hedlund et al. [6-7] reviewed a variety of devices and geometries to produce swirl in internal flows. They studied another swirl chamber which employed tangential jets from wall slots or ducts to produce large scale swirling in internal tube flows. The changes of local Nusselt number for this swirl chamber are investigated for variable Reynolds numbers and ratios of inlet temperature to wall temperature. The aim is to show the velocity and pressure distribution in diffuser.

In this research, a new method is used to simulate the air flow from the swirling diffuser. In this method, the CFD simulation domain is extended into the supply air duct and the detailed air flows between the swirling vanes and the precombustion chamber are included. The commercial CFD code APDL is used. The simulation results are reviewed below.

\section{Grid Generation}

The numerical flow simulation is satisfied using ANSYS 11 package to solution of flow problems. The commercial software (ANSYS) built on finite element method (FEM). The approximation of the (FEM) depends on the type of mesh generation and size of element cell. There are two types of mesh generation are structure mesh and unstructured mesh. The types of mesh depend on the feacher of points connectivity. The diffuser without meshing is shown in figure (1). The both types of mesh generation is used in this research and can be shown in figure (2). The numerical results accuracy extensive reliance on optimization mesh generation.

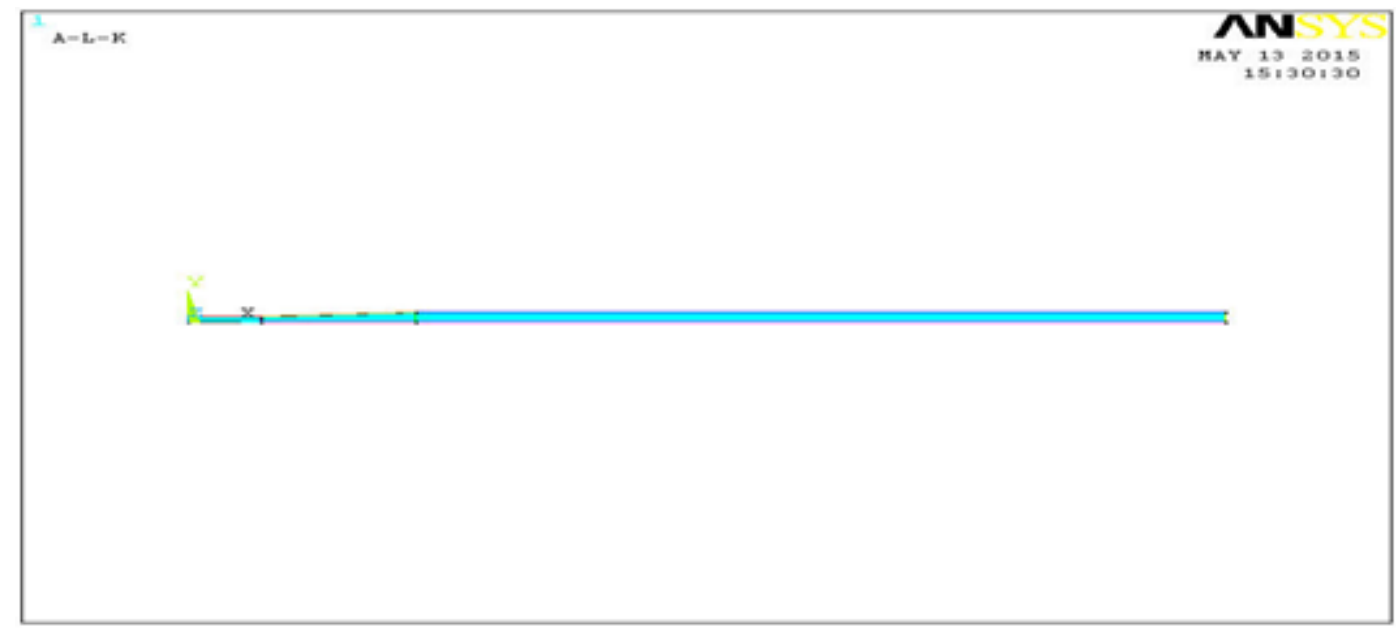

Figure 1: The diffuser without meshing 


\section{International Journal of Science and Research (IJSR) \\ ISSN (Online): 2319-7064}

Index Copernicus Value (2013): 6.14 | Impact Factor (2014): 5.611

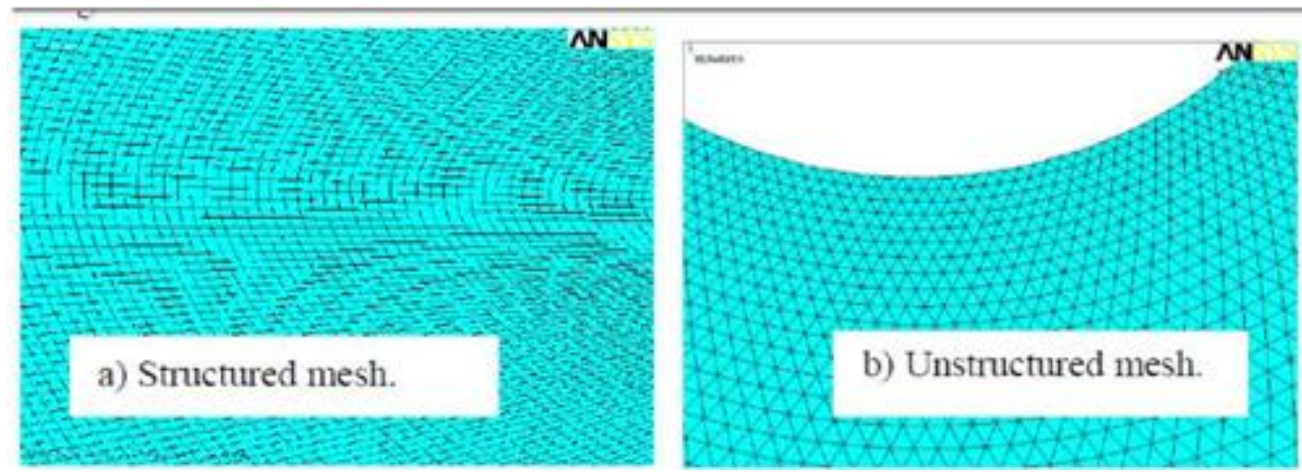

Figure 2: Types of mesh generation

The optimization mesh generation can be predicted by experimented numerically solution of random point until reach to excepted accuracy by increases the number of elements and decreases element size. The pressure iteration convergence reach to $10^{-4}$ and velocity components $\mathrm{u}$ and $\mathrm{v}$ iteration convergent until $10^{-6}$.

The convergence criterion of pressure and velocity components used to solve continuity and momentum partial differential equations with stable iteration results is very fine to get accuracy results under relaxation parameter equal to 0.5 .

\section{Theoretical Approximation and Boundary Conditions}

In this research, the efforts devoted to study the effect of turbulent air flow on fluid properties such as pressure and velocity distribution. The k-omega turbulence model is used to analysis the air flow in diffuser. The model assumptions can be summarized in the following points:

1. Steady state (onset turbulent flow situation).

2. Incompressible.

3. The inlet velocity of air $=20 \mathrm{~m} / \mathrm{s}$.

4. The exit pressure of air in diffuser is equal to atmospheric pressure.

5. The velocity of flow very close to solid wall equal to zero (by viscosity effect).

6. The effect of inertia force is greater than the viscosity (will get turbulent flow).

For predicting the flow type, the Reynolds number was calculated first.

$$
\operatorname{Re}_{\mathrm{D}}=\frac{\rho V D}{\mu}
$$

The conservation equations can be summarized as below:

a) Continuity equation [8] and [9].

$$
\frac{\partial u}{\partial x}+\frac{\partial v}{\partial y}=0
$$

b) The momentum equations in $\mathrm{x}$-direction:

$$
\mathrm{P}\left(\mathrm{u} \frac{\partial \mathrm{u}}{\partial \mathrm{x}}+\mathrm{v} \frac{\partial \mathrm{u}}{\partial \mathrm{y}}\right)=-\frac{\partial \mathrm{p}}{\partial \mathrm{x}}+\frac{\partial}{\partial \mathrm{x}}\left(2 \mu_{\text {eff }} \frac{\partial \mathrm{u}}{\partial \mathrm{x}}\right)+\frac{\partial}{\partial y}\left(2 \mu_{\text {eff }} \frac{\partial \mathrm{u}}{\partial y}\right)
$$

c) The momentum equations in y-direction:

$$
\mathrm{p}\left(\mathrm{u} \frac{\partial \mathrm{u}}{\partial \mathrm{x}}+\mathrm{v} \frac{\partial \mathrm{u}}{\partial y}\right)=\mathrm{p} g_{y}-\frac{\partial \mathrm{p}}{\partial y}+\frac{\partial}{\partial \mathrm{x}}\left(2 \mu_{\text {eff }} \frac{\partial \mathrm{v}}{\partial \mathrm{x}}\right)+\frac{\partial}{\partial y}\left(2 \mu_{\text {eff }} \frac{\partial \mathrm{v}}{\partial \mathrm{y}}\right)
$$

where

\section{$\mu_{\text {eff }}=$ effectiveviscosity}

Where the flow is turbulent, the velocity in $\mathrm{x}$ direction involving the mean component $\bar{u}$ and the fluctuation component $\bar{u}$ as shown in equation below:

$$
\mathrm{u}=\bar{u}+\bar{u}
$$

also, the velocity in y direction involving the mean component $\bar{v}$ and the fluctuation component $\vec{v}$ as shown in equation

$$
v=\bar{v}+\vec{v}
$$

For turbulent flow we get the Reynolds stress $(\sigma)$ in term of : $\mathrm{x}\left(\sigma_{x}\right)$ and $\mathrm{y}\left(\sigma_{y}\right)$ direction that which introduced in momentum equations below:

$$
\begin{aligned}
& \sigma_{x}=-\frac{\partial}{\partial x}\left(\rho u^{\prime} u^{\prime}\right)-\frac{\partial}{\partial y}\left(\rho u^{\prime} v^{\prime}\right) . \\
& \sigma_{x}=-\frac{\partial}{\partial x}\left(\rho v^{\prime} u^{\prime}\right)-\frac{\partial}{\partial y}\left(\rho v^{\prime} v^{\prime}\right) .
\end{aligned}
$$

Also, an effective viscosity is defined as the sum of laminar viscosity and turbulent viscosity.

$$
\mu_{\text {eff }}=\mu+\mu_{\mathrm{t}}
$$

\section{Results and Discussion}

The flow visualize can be simply illustrated depends on flow stream line. The stream lines were generated. Moreover, the stream lines refer to the flow direction. The relation between the normalized rate change and cumulative iteration number is shown in figure (3). Figure (4) presents the variation of pressure with distance. The pressureis the vacuum at the inlet air to diffuser while increases at the exit air from diffuser as shown in figure (5). Moreover, the pressure increases with increasing air velocity at the exit of the diffuser as shown in figure (6). 


\section{International Journal of Science and Research (IJSR) \\ ISSN (Online): 2319-7064}

Index Copernicus Value (2013): 6.14 | Impact Factor (2014): 5.611

Time $=0$

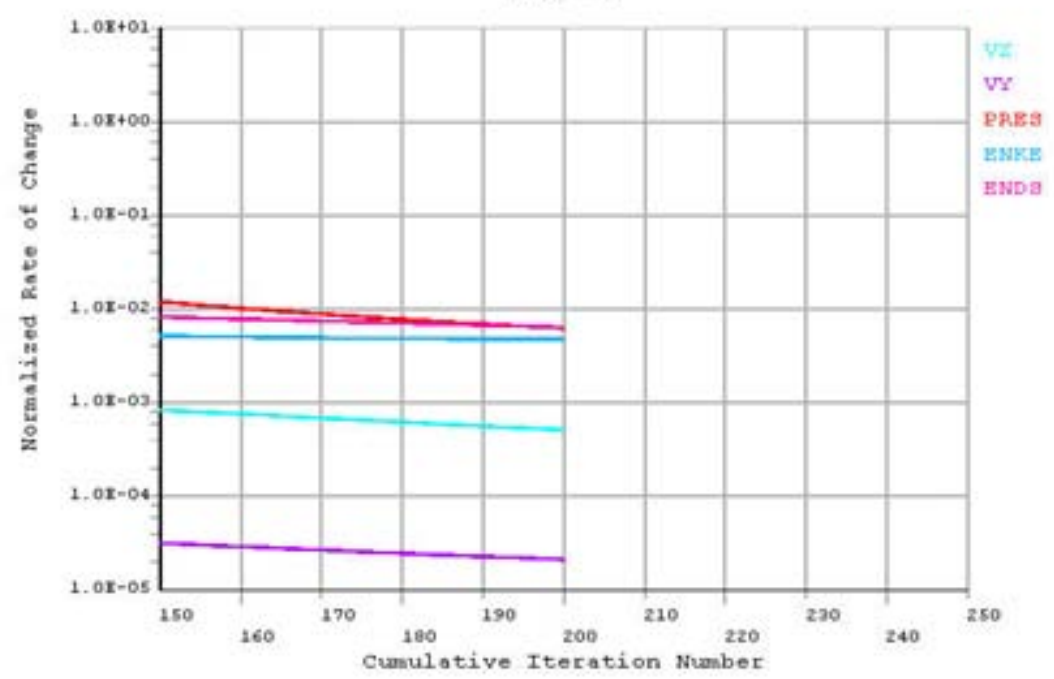

Figure 3: The relation between the normalized rate change and cumulative iteration number

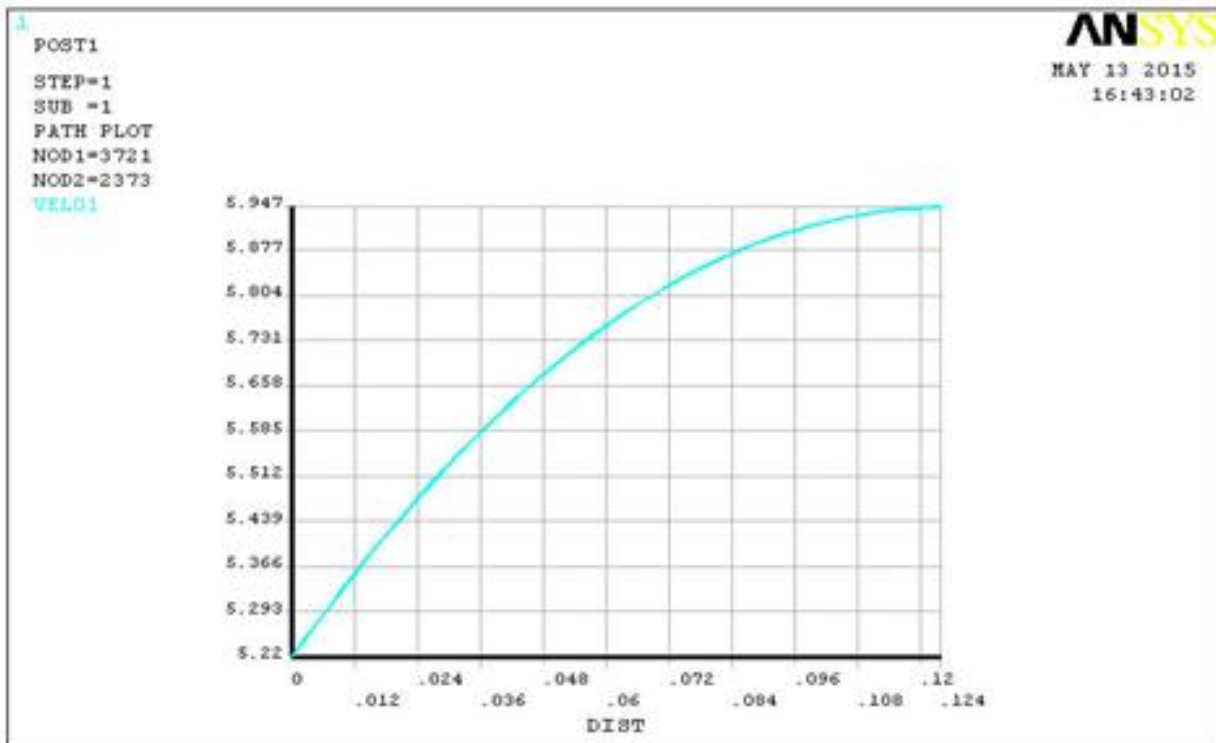

Figure 4: The variation of the air pressure with distance

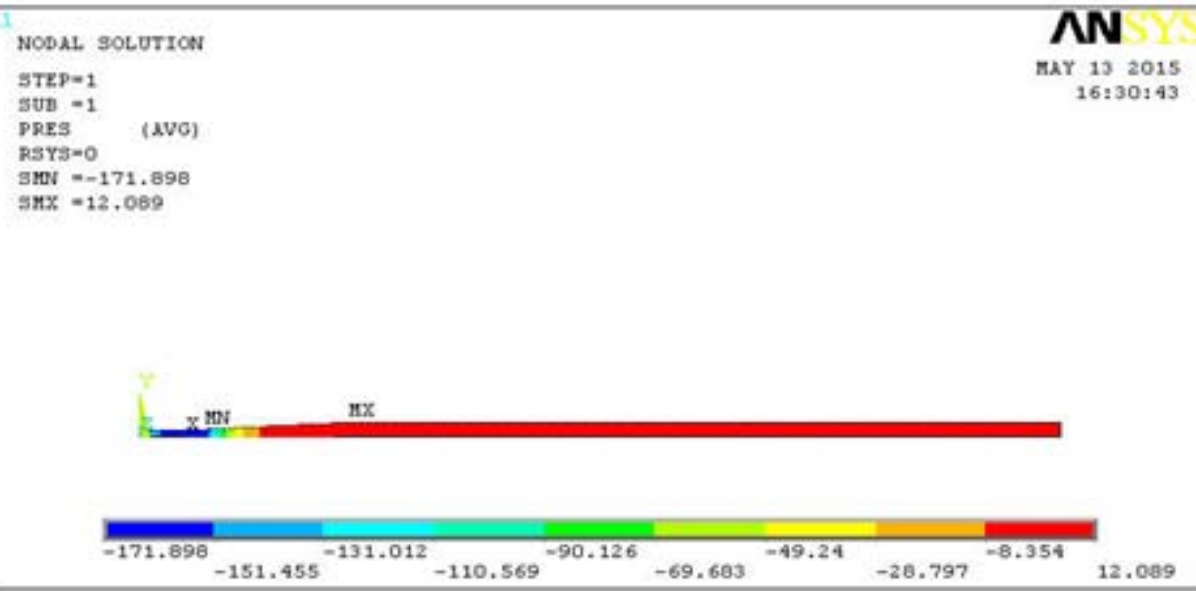

Figure 5: Contour pressure distribution in diffuser

Volume 5 Issue 1, January 2016

www.ijsr.net 


\section{International Journal of Science and Research (IJSR)}

ISSN (Online): 2319-7064

Index Copernicus Value (2013): 6.14 | Impact Factor (2014): 5.611

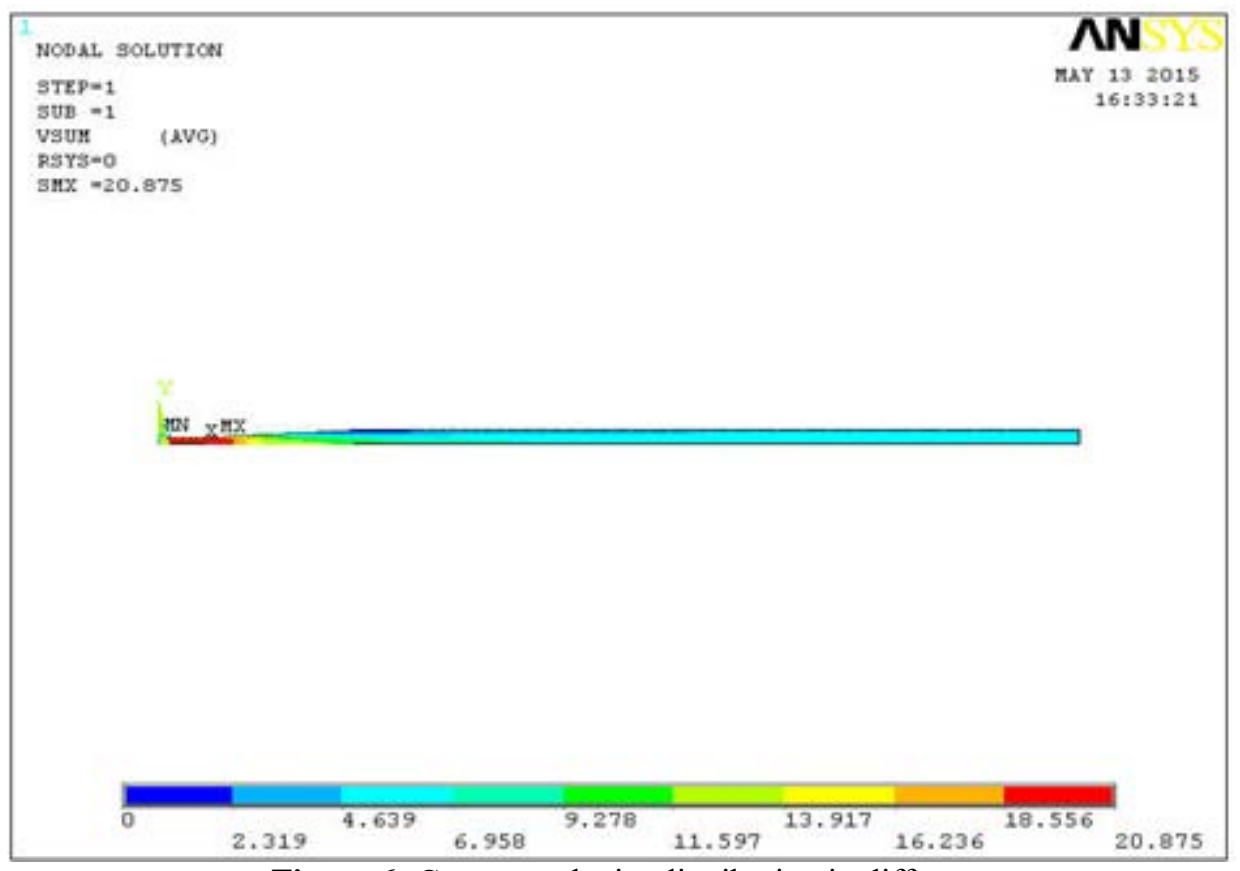

Figure 6: Contour velocity distribution in diffuser

\section{Conclusions}

The aim of this research is to investigate effect of turbulent air flow on the pressure and velocity distribution of air in diffuser.The conclusions can be summarized in the following:

The air pressure decreases gradually and the maximum pressure occurs at the inlet of air to diffuser. Also, the air velocity increases gradually. The maximum velocity happens at the exit of diffuser.

\section{References}

[1] F. Kreith and D. Margolis, Heat Transfer and Friction in Turbulent Vortex Flow, Appl. Sci. Res, vol.8, pp. 457473, 1959.

[2] T. W. Davies and J.M. Beer, Flow in the Wake of BluffBody Flame Stabilizer, $13^{\text {th }}$, sym.(Int.) on Combustion, pp. 80-1190, 1971.

[3] B. Zhou, X. L. Wang, R. X. Li and L. X.Zhou, Swirling Gas- Particle Flows and Coal Combustion in a Spouting- Cyclone Combustor, ASME, Heat Transfer, Div. HTD- vol.250, pp.243-247, 1993.

[4] J. A. Visser and J.Du Plessis, Swirling Flow in a Closed Combustion Chamber, Second Int. Conf. on Advanced Computational Methods in Heat Transfer, pp. 665-676, 1992.

[5] J.D. Singer, Combustion Engineering, Combustion Engineering Inc., Windsor, pp. 4-33., 1981.

[6] C. R. Hedlund, P. M. Ligrani, H. K. Moon and B. Glezer, Heat Transfer and Flow Phenomena in a Swirl Chamber Simulating Turbine Blade Internal Cooling, Trans. ASME, J. Turbomach., vol.121, no.4, pp. 804813, 1999.

[7] . R. Hedlund, P. M. Ligrani, Local Swirl Chamber Heat Transfer and Flow Structure at Different Reynolds Numbers, Trans. ASME, J. Turbomach., vol.122, no.2, pp. 375-385, 2000.
[8] Donghyun You, Frank Ham and Parviz Moin., Discrete Conservation Principles in Large Eddy SimulationWith Application to Seperation Control over an Airfoil, Physics of Fluids, vol.20, Issue 10, special topic, turbulence physics and control, papers from a workshop in honor of john kim's $60^{\text {th }}$ birthday, Stanford, California, September, 2007.

[9] Jack Moran,An Introduction to Theoretical and Computational Aerodynamics, University of Minnesota, Copyright 1984, by John Wiley \& Sons. Inc. 